well as the paper "Linking the Salton Sea with its past: the History and Avifauna of Lake Cahuilla" will give you a much more thorough context-setting. We learn of the significance of the Salton Sink not only to its immediate surroundings but as a piece of the Colorado River Delta Region, itself radically altered over the last century.

As the authors of "History of Ornithological Exploration of the Salton Sink" point out, thanks to a strong naturalist tradition among earlier visitors to the region, studies began there before the present Salton Sea was created. This paper, and "Population changes and biogeographic affinities of the birds of the Salton Sink, California/Baja California" express the status, ecology and changes over a remarkably compact time period. The permanent water body has been in place for only 100 years, and ornithologists have been observing there, to varying degrees, for most of that time.

The Salton Sink is important for its locally breeding species (it hosts several regionally significant species and subspecies); as a migratory stopover or wintering territory for huge numbers of landbirds, waterbirds, waterfowl and shorebirds; and for its numerous records of vagrant or visiting pelagic and waterbirds via the Gulf of California. Not surprisingly, wetlands and associated species account for much of the focus of these papers. However, all bird groups present get some coverage, including landbirds with their dependence on riparian zones, and Burrowing Owls, whose population rose as land was converted by irrigation from Sonoran desert to agricultural.

Two additional papers discuss disease patterns: type $\mathrm{C}$ avian botulism, and the largest as-yet documented die-off of Eared Grebes which remained, at time of publishing, unexplained. Avian cholera was present in some birds, high amounts of contaminants in others, but nothing had yet satisfactorily accounted for the extent of the die-off.

In the final paper, "The Salton Sea: A Conservation Conundrum or Paradigm for Success?" the editors discuss just that: do the region's complicated past and present mean it will ultimately be impossible to restore and maintain a healthy ecosystem, or is this a living laboratory leading to a model that can succeed here, and elsewhere? There remain many problems to solve, they admit, and all manner of social and political challenges.

As a compilation and analysis of baseline and other studies, this work should be an important part of the scientific literature for the region. It would also serve, if not as a model, at least as a reflection piece for environmental conservation workers anywhere, and certainly in locations analogous to this one, wherever they may be. The volume is consistently edited, the papers well-written. Although technical, they are not loaded with jargon. Abstracts are in English and Spanish. The citations from all the papers are combined in one "Literature Cited" section, making a very handy, comprehensive bibliography. One expects this type of work to be aimed at scientific and other professionals, but given the diverse interests in this region, with its large transnational population and vanishing natural habitats, I believe it is a great service that this collection is readable enough to engage a curious and concerned public as well.

BEV MCBRIDE

574 Tweedsmuir Avenue, Ottawa, Ontario K1Z 5P2 Canada

\title{
Amur Tiger
}

By D. Prynn, Russian Nature Press (http://www.rusnatpress. org.uk/). 200 pages. 33 USD.

This very nice book gives great and entertaining information on the fascinating Amur Tiger. It is devoted to the great Russian naturalist and tiger expert: E. $\mathrm{N}$. Matyushkin. This well-written and balanced text shows that this wildlife and conservation subject is a rather complex one: it deals not only with the vast Soviet Russian history, but also with today's Russia, with China as well as with a diverse set of stakeholders, including American and industrial ones (e.g., NGOs [nongovernment organizations] supported by Exxon Mobil and Shell; complete list is given in the Appendix). Interspersed with biological details are the nice and fascinating translated Russian writings by V.K. Arseniev, N.A. Baykov and others about Amur Tigers, their habitats and haunts (just the authors of these text sections alone are already worth several books). Amur Tigers live primarily in the Primorye region, Russian Far East, with Sikhote Alin and Amur river as its core, and the bordering China and North Korea region. This

region is part of the Pacific Rim and offers a unique biodiversity with many endemic and fascinating species (the mountain range of Sikhote Alin has over 1000 plant species for instance).

The English author is familiar with these subjects and presents us a well-balanced text and scholastic tiger information.

This book makes for a great case that western-style development is in direct conflict with splendid animals like the tiger. China's tiger population is already on the verge of extinction, and all Tiger populations world-wide are either extinct, or significantly reduced in their distribution and population. Only the Russian stock is the largest, and currently somewhat expanding (urbanization, global warming and intense resource use in this region are making its fate worse though).

This informative book focuses also on traditional tiger biology and habitat descriptions. I like the sections on prey, which support the case to consider the entire food chain and ecosystem for a meaningful conservation management. The text makes for a nice and 
easy to read monograph, bringing the Russian Far East and its environs closer to a wider audience. This further gets achieved by the nice drawings and maps (no photos though). The four Appendices help to reach this goal further. I really appreciate the 16 pages of Notes. The presented literature is more from mainstream magazines, but it sufficiently allows the reader to get started on the topic.

The authors make clear that the Chinese tiger management policy, only focusing on captive breeding (e.g., at the breeding station in Harbin), but ignoring virtually all habitat issues, is more than dubious. The demand for tiger parts for Traditional Medicine gets widely cited for declines ('Operation Tiger' confiscated over 5000 snares in one campaign alone).

There is one flaw with this book: it does not make the direct link to the real problem in most carnivore and wildlife conservation: Traditional-style Economic Development, such as promoted in Russia, China, and most parts of the world these days, e.g., via the Asian Development Bank, will finish off the splendid tiger. For instance, the prey-base for these animals is already not sufficient, nor are the currently protected zones. Hydro-dam projects are not mentioned by the authors (a major issue in the Amur River basin), nor is climate change. China just got granted two Russian islands in the Amur basin for their economic development, and the incredibly high Chinese demand for wood - the highly valued Korean Pine (Pinus koraiensis) - already widely cited for greatly contributing to habitat loss for tigers and their prey. Further problems occur through massive poaching and other development efforts. It is unclear to me why the Russian Government, one of the leading oil and gas producers in the world, and thus equally as rich as Saudi Arabia, is not able to support science-based Tiger conservation, and requires international assistance from NGOs and experts. Why does the international community let this happen?

This nice book should at least be read by every naturalist interested in Russia, Asia, wilderness, carnivores and cats. In times of globalization, it brings us one of the ten largest river systems - its ecosystem and wildlife - and with the tiger as its flagship species, closer to home.

FALK HUETTMANN

EWHALE laboratory, Institute of Arctic Biology, Biology \& Wildlife Department, University of Alaska-Fairbanks, Fairbanks, Alaska 99775 USA

\section{BOTANY}

\section{Woody Starch Plants in China}

By Xie Bixia, Xun Chen, Donglin Zhang, Wenbin Liang, Qiuping Zhong, Sen Wang, Riqing Zhang, Anping Li, Xiaofang Pan, Yafeng Wen, Hongwen Zhuang, Tao Wu, Zhanying Gu, Xinjian Wang, Jiangfan Yu, and Manhui Hu. 2008. Science Press, Beijing, China. 360 pages, 88.00 CNY.

Starch (amylum) is a complex carbohydrate, a polysaccharide made up of a large number of linked glucose molecules (monosaccharides). In plants, starch is a by-product of photosynthesis, being mainly composed of two types of glucose polymer, the amylose and the amylopectin. It is an important and effective means of storing excess glucose as the form of energy for future use for the majority of plants. Starch, as a insoluble material, usually is stored in plant cells without impact on the water potential of cells, and thus may be stored in large amounts without disrupting the water potential of the cells. In plants, starch usually exists in the form of organized grains of various sizes and shapes, depending on the species of plant.

The primary production of plants forms the base of food chain or web of an ecosystem and fuels the whole ecosystem. Consumption of the primary producers by the heterotrophic organisms, and then transference of these organic molecules as well as the energy stored within them up the food chain or web, results in the energy flow of the ecosystem. In the whole process, starch as a form of energy storage plays important roles. Starch is the major form of carbon reserve in plants, especially in the fruits, seeds, rhizomes or tubers. Some net primary production containing starch will go towards growth and reproduction of the primary producers, while some other parts will be consumed by herbivores. In some important starch plants, a category of plants containing abundant starch, it constitutes $50 \%$ or more of the dry weight of many storage organs. Starch must first be converted to a soluble form before being used by the plant itself, but if used by the heterotrophic organisms, it can be digested directly.

The lives of human beings are closely related to various types of plants, among which the starch plants are particularly important since they usually act as the source of daily food or industrial materials. Although the woody starch plants are not popularly used in the daily lives by human beings as much as some agriculturally important starch plants (most of them are graminaceous plants), some of them are frequently, or at least sometimes, consumed. Many woody starch plants still remain as wild plants, unexploited or even undiscovered, while only a few species have been exploited and used by human beings. Most of the woody starch plant species must have, or potentially have, value due to their abundant content of starch. Since the wild woody starch plants are usually pollution-free, 